\title{
Canopy recovery after drought dieback in holm-oak Mediterranean forests of Catalonia (NE Spain)
}

\author{
FRANCISCO LLORET*, DANIEL SISCART* and CARLES DALMASES † \\ *Center for Ecological Research and Forestry Applications (CREAF), Departament de Biologia Animal, Biologia Vegetal i Ecologia, \\ Universitat Autònoma de Barcelona, 08193 Bellaterra, Barcelona, Spain, $\dagger C R E A F$, Universitat Autònoma de Barcelona, \\ 08193 Bellaterra, Barcelona, Spain
}

\begin{abstract}
Climate change is likely to produce more frequent and longer droughts in the Mediterranean region, like that of 1994, which produced important changes in the Quercus ilex forests, with up to $76 \%$ of the trees showing complete canopy dieback. At the landscape level, a mosaic of responses to the drought was observed, linked to the distribution of lithological substrates. Damage to the dominant tree species $(Q$. ilex) and the most common understorey shrub (Erica arborea) was more noticeable on the compact substrates (breccia) than on the fissured ones (schist). This result was consistent with observations documenting deeper root penetration in schist than in breccia materials, allowing the plants growing on fissured substrates to use water from deeper soil levels. Smaller plants were more vulnerable to drought than larger plants in the trees, but not in the shrubs. Overall, $Q$. ilex was more affected than E. arborea. The resilience of the system was evaluated from the canopy recovery 1 year after the episode. Stump and crown resprouting was fairly extensive, but the damage pattern in relation to substrate, plant size, and species remained similar. The effect of recurrent drought episodes was studied on vegetation patches of $Q$. ilex located on mountain slopes and surrounded by bare rock. We observed that plants that resprouted weakly after a previous drought in 1985 were more likely to die or to produce poor regeneration in 1995 than plants that had resprouted vigorously. Vegetation patches located on the lower part of the slope were also less damaged than patches situated uphill. The study provides evidence of relevant changes in forest canopy as a consequence of extreme climate events. The distribution of this effect across the landscape is mediated by lithological substrate, causing patchy patterns. The results also support the hypothesis that recurrent droughts can produce a progressive loss of resilience, by depleting the ability of surviving plants to regenerate.

Keywords: climate change, Erica arborea, Quercus ilex, resilience, resprouting, severity, shift, threshold

Received 18 February 2004; revised version received 2 June 2004 and accepted 4 June 2004
\end{abstract}

\section{Introduction}

Predictions resulting from global vegetation models are commonly based on the equilibrium principle between climate and large vegetation units (biomes) (Hurtt et al., 1998). Less emphasis has been put on the transient changes at smaller temporal scales (Steffan et al., 1996), in spite of some warning calls about the importance of climatic between-year variability (Woodward \& Beerling, 1997), and increased backing for the supposition that extreme climatic events may become more frequent

Correspondence: Francisco Lloret, fax + 3493581 4151, e-mail: Francisco.Lloret@uab.es
(IPCC, 2001). In fact, these extreme events can be interpreted as a result of the scale of observation of thresholds. We can observe a gradual drop in precipitation by averaging 10-year periods, but this decrease can be the result of a few years of extreme drought. If the relevant ecological processes (such as mortality) occur on shorter time scales, we can observe nonlinear responses and shifts on broader scales (Scherm \& van Bruggen, 1994).

Drought-related tree dieback in forests has recently been documented in different temperate and tropical ecosystems (Allen \& Breshears, 1998; Villalba \& Veblen, 1998; Fensham \& Holman, 1999). In Mediterraneantype ecosystems, several reports indicate significant 
mortality of shrubs when prolonged drought occurs (Hobbs \& Mooney, 1995), and palaeobotanical records show abrupt shifts of vegetation associated with past climate change (Carrión et al., 2001). In 1994, an extreme drought event produced a general dieback of trees in the southern and eastern regions of the Iberian peninsula (Peñuelas et al., 2000). A previous drought episode in 1985 also caused tree dieback in some areas of Catalonia (NE Spain). Climate change models predict a warming in winter and summer and a decrease in summer rainfall in the Mediterranean regions (Palutikof \& Wigley, 1996), but, overall, an increase in rainfall variability (Summer et al., 2003), and, particularly, extreme drought episodes is expected as well (IPCC, 2001).

Mediterranean-type ecosystems have also been documented as being highly resilient to disturbances (Malanson \& Trabaud, 1987). Resilience has been defined as an ecosystem's capacity to recover its characteristics after a disturbance. In addition to the precipitating events, ecosystem shifts can occur as a consequence of a gradual loss of resilience (Scheffer et al., 2001). Recurrent disturbances may contribute to this reduction in the ability of the ecosystem to recover (Díaz-Delgado et al., 2002). After disturbance, resprouting from surviving organs, particularly from belowground structures, is a common trait in many trees and shrubs of the Mediterranean regions (Canadell \& Zedler, 1995), and this process contributes to the maintenance of the same type of community. The resprouting response depends on the damage caused by the disturbance, and the ability to mobilize resources after the disturbance (Canadell \& López-Soria, 1998). In the case of the drought-related dieback observed in Catalonia, a widespread resprouting was observed 1 year after the drought episode (Peñuelas et al., 2000).

In this study, we analyse the effect of a drought episode on the canopy of a Mediterranean forest, and the crown recovery 1 year later. We surveyed the damage wrought by the 1994 drought on the dominant tree Quercus ilex L., and Erica arborea L., a common shrub in the understorey. We compared the severity of the drought and the forest resilience in areas with two different substrates (schist and breccia) that have a different suitability for root penetration and are likely to generate distinct patterns of damage at landscape level. We also analysed the effect of plant size on drought severity and postdieback regeneration. The consequences of previous drought events, such as the 1985 episode, were evaluated by correlating the resprouting response after the 1994 episode with the resprouting occurring in 1985 . This part of the study was performed in vegetation patches with limited soil, located on mountain slopes. We hypothesize that:
(1) substrate determines vegetation vulnerability to extreme climatic events, contributing to the existence of response thresholds on spatial and time scales; (2) disturbance severity and resilience are influenced by plant size; (3) recurrent droughts produce accumulative effects that diminish the regenerative capacity of the species.

\section{Materials and methods}

\section{Species description and study sites}

Q. ilex L. (holm-oak) is an evergreen, sclerophyllous tree, widely distributed along the Mediterranean Basin, from cold, semiarid to temperate, humid bioclimates, forming dense canopies in single or mixed forests (Terradas, 1999). E. arborea L. is a long-living, evergreen shrub, common in heathlands and in the forest understorey of the Western Mediterranean Basin. Both species are able to resprout strongly after disturbance from lignotubers (E. arborea) or stumps (Q. ilex).

The effect of a single drought event was studied in six sites dominated by evergreen, holm-oak ( $Q$. ilex) forests, located throughout the Catalonian Prelitoral range (NE Spain), from 420 to $680 \mathrm{~m}$ a.s.l., and about 20-30 km from the coast (see Table 1 for detailed location). All sites showed similar geological features, characterized by a contact between Palaeozoic, schist shales (hereafter, schist) and Tertiary breccia with siliceous clastic materials (hereafter, breccia). These two types of substrate show different suitability to deep root penetration, since schist allows roots to reach deep layers following exfoliation planes as preferred pathways, while breccia produces a compact substrate matrix that hinders root penetration (Canadell et al., 1999). Both types of substrate develop moderately acid soils where holm-oak forests grow with similar composition and structure (see Table 1 for information about stand basal area). Coppicing for firewood and charcoal was highly developed in these forests until the 1950s, but no evidence of any recent major disturbances are currently visible. The forests are dominated by $Q$. ilex, although individuals of Phillyrea latifolia and Arbutus unedo can occasionally reach the canopy. Common species in the understorey are E. arborea, A. unedo, Rosmarinus officinalis, Cistus monspeliensis, C. albidus and C. salviifolius. We focused our study on the two dominant species of canopy and understorey, Q. ilex and E. arborea, respectively.

The study of the effect of recurrent drought episodes was conducted on an additional site of the same area, on the Montcau Mountain (Sant Llorenç and Serra de l'Obac Natural Park), from 910 to $1030 \mathrm{~m}$ a.s.l., and about $25-30 \mathrm{~km}$ from the coast. The mountain is 
Table 1 Sites description including location, stand basal area (BA), H (from dbh) and number of sampled plants per species

\begin{tabular}{|c|c|c|c|c|c|c|}
\hline & \multirow[b]{2}{*}{ Location } & & \multirow[b]{2}{*}{ Altitude (m) } & \multirow[b]{2}{*}{ HBA $(\mathrm{dbh})\left(\mathrm{m}^{-2} \mathrm{ha}^{-1}\right)$} & \multicolumn{2}{|c|}{ Number of sampled plants } \\
\hline & & & & & Quercus ilex & Erica arborea \\
\hline Girbau & $41^{\circ} 37^{\prime} 24^{\prime \prime} \mathrm{N}$ & $2^{\circ} 02^{\prime} 27^{\prime \prime} \mathrm{E}$ & 620 & 24.6 & 400 & 400 \\
\hline Pedritxes & $41^{\circ} 37^{\prime} 07^{\prime \prime} \mathrm{N}$ & $1^{\circ} 58^{\prime} 50^{\prime \prime} \mathrm{E}$ & 680 & 12.5 & 100 & 100 \\
\hline Rellinars & $41^{\circ} 37^{\prime} 32^{\prime \prime} \mathrm{N}$ & $1^{\circ} 55^{\prime} 13^{\prime \prime} \mathrm{E}$ & 420 & 20.4 & 200 & 200 \\
\hline Caus & $41^{\circ} 36^{\prime} 51^{\prime \prime} \mathrm{N}$ & $1^{\circ} 56^{\prime} 40^{\prime \prime} \mathrm{E}$ & 480 & 21.9 & 300 & 300 \\
\hline Mosset & $41^{\circ} 35^{\prime} 24^{\prime \prime} \mathrm{N}$ & $1^{\circ} 43^{\prime} 48^{\prime \prime} \mathrm{E}$ & 590 & 34.3 & 200 & 150 \\
\hline Morelles & $41^{\circ} 35^{\prime} 06^{\prime \prime} \mathrm{N}$ & $1^{\circ} 42^{\prime} 53^{\prime \prime} \mathrm{E}$ & 610 & 5.3 & 100 & 100 \\
\hline
\end{tabular}

$\mathrm{dbh}$, diameter at breast height.

covered by a mosaic of bare bedrock (Eocean calcareous conglomerates) and vegetation patches dominated by $Q$. ilex. This site was selected because the vegetation growing on these patches is particularly vulnerable to water deficit stress, because of the shallow soils developed on them. We selected 18 vegetation islands (ranging from 1.3 to $24.8 \mathrm{ha}$ ), at different aspects and positions on the slope (six on the upper part of the slope, six on the middle and six on the lower part).

In all the studied areas, the climate is Mediterranean; at the nearby weather station of Igualada ( $320 \mathrm{~m}$ a.s.l.), mean monthly temperature is $13.9^{\circ} \mathrm{C}$, and mean annual precipitation is $605 \mathrm{~mm}, 20 \%$ of which falls in summer. In 1985, a drought episode from December 1984 to September 1985 produced a reduction in rainfall of around $45 \%$, compared with the normal precipitation. In 1993 and 1994, another extreme drought episode occurred throughout the Iberian Peninsula (Peñuelas et al., 2001), resulting in a decrease of around $50 \%$ of the normal rainfall in the study area from November 1993 to August 1994 (Ninyerola et al., 2000, Fig. 1). Normal levels have been recorded again since September 1994. This rainfall reduction similarly affected the whole sampled area. Severe dieback in forest canopy was observed as a result of the last drought episode.

\section{Dieback and resprouting survey}

For the study of the single 1994 drought event, the extent of visible damage to $Q$. ilex and E. arborea was quantified at the end of summer 1994 in both schist and breccia substrates of each site. We performed direct observations of the bedrock to ensure the location of the surveys on the respective substrate. On each substrate, $2 \mathrm{~m}$ wide transects were randomly laid out perpendicular to the slope, and the 50 first individuals belonging to $Q$. ilex and E. arborea were surveyed. On each site, we established the same number of transects in the two types of substrate, but this number varied between sites from two to eight (see Table 1 for details on the number

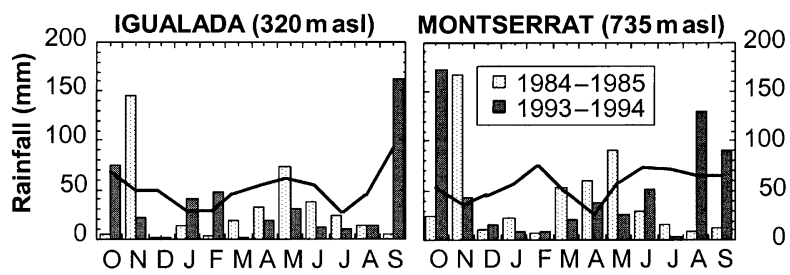

Fig. 1 Monthly rainfall during the two drought periods in two localities covering the whole range of elevations where the survey was performed. Solid lines indicate average values of rainfall obtained from 20-year records (http://magno.uab.es/ atles-climatic, Ninyerola et al., 2000).

of plants sampled in each location). Only in one transect did the low density of E. arborea preclude its survey.

Three class sizes were considered for $Q$. ilex individuals: saplings (less than $50 \mathrm{~cm}$ height, less than $5 \mathrm{~cm}$ diameter at breast height $(\mathrm{dbh})$ ), small trees (more than $50 \mathrm{~cm}$ height, but less than $5 \mathrm{~cm}$ dbh) and large trees (more than $5 \mathrm{~cm} \mathrm{dbh).} \mathrm{Two} \mathrm{size} \mathrm{classes} \mathrm{were}$ considered for $E$. arborea individuals: small shrubs (height less than $50 \mathrm{~cm}$ ), and large shrubs (height more than $50 \mathrm{~cm}$ ). All Q. ilex and E. arborea individuals were tagged and classified into the following classes, according to the percentage of remaining green leaves:

0 : no remaining green foliage;

1: $25 \%$ remaining green foliage;

2: $26-75 \%$ remaining green foliage;

3: $76-100 \%$ remaining green foliage.

We surveyed the recovery of the canopy of each individual at the end of summer 1995 by using the same categories. Three categories of recovery type were recognized: from stump, from crown, or from both stump and crown.

For the study of recurrent drought episodes, in spring 1996 we surveyed all Q. ilex plants present in a $100 \mathrm{~m}^{2}$ stand randomly located within each vegetation islands. In this case, saplings were excluded from the study, and 
we considered three class sizes of adults: small $(\mathrm{dbh}<10 \mathrm{~cm})$, medium $(10 \mathrm{~cm}<\mathrm{dbh}<20 \mathrm{~cm})$ and large $(\mathrm{dbh}>20 \mathrm{~cm})$. We distinguished old sprouts from new ones. Old sprouts were lignified shoots, and we assumed that they were mostly produced after this 1985 drought event, because no other major disturbance had occurred in the area since that time. Stems and large branches that were dead as a consequence of the 1985 drought were not included in the survey. They could be recognized because they were standing on the tree in an advanced state of decomposition. New sprouts grew after the 1994 drought, and these were green and produced new buds and leaves.

We established the following plant categories in relation to the 1985 and 1994 drought episodes:

0 : dead plant;

1: weak resprouting, covering less than $50 \%$ of the damaged canopy;

2: strong resprouting, covering more than $50 \%$ of the damaged canopy;

3: undamaged plant, no resprouting.

\section{Data analysis}

The effect of drought on canopy was analysed by a three-way ANOVA, with species and substrate as fixed factors and locality as random factor. The dependent variable was the percentage of green leaves recorded at the end of the 1994 summer. For this purpose, we averaged the range of the four damage classes as $0 \%$, $12.5 \%, 50 \%$, and $87.5 \%$ of green leaves, respectively. The number of replicates was different in each locality, since we pooled the values of the different transects within each type of substrate. We analysed the effect of drought on the different size classes separately for each species by three-way ANOVAs with size and substrate as fixed factors, and locality as random factor. We used the same dependent variable as described above.

Differences between species in canopy recovery were analysed by repeated ANOVA measures with species as between-factor variable, and canopy state in 1994 and 1995 as within-factor (repeated measures) variable. This analysis was also performed for each species to evaluate the differences in canopy recovery between substrate, to analyse differences between size classes, and to analyse differences between the three types of recovery (stump, crown, and both stump and crown).

The effect of the vegetation islands' position on the slope with respect to $Q$. ilex survival was analysed by $\chi^{2}$ tests, after pooling all the trees growing in the same slope position. The same test was used to correlate the resprouting status after the 1994 and 1985 drought episodes, and to evaluate the resprouting differences among size classes. For these analyses, we only considered the following categories: weak and strong resprouting after 1985, dead plants, weak and strong resprouting after 1994.

All analyses were performed following the Statview 4.5 (Abacus Concepts Inc., Berkeley, CA, USA) procedure. No transformations were needed to attain the homoscedastic and additive criteria.

\section{Results}

Substrate largely determined the effect of climate drought on trees and shrubs of the dominant species $Q$. ilex and E. arborea $\left(F_{1,5}=198.86, P<0.001\right)$. Indeed, survival was significantly greater on schist than breccia substrate for every single site for both species (Fig. 2). In Q. ilex, the mean percentage of green leaves was 10.6 in breccia and 55.4 in schist. E. arborea showed a similar pattern, but with significantly higher percentages of green leaves (19.4 in breccia, 61.9 in schist) $\left(F_{1,5}=7.95\right.$, $P=0.037$ ). The percentage of $Q$. ilex plants with complete loss of foliage was 75.9 in breccia and 23.2 in schist. In E. arborea, these percentages were 53.7 and 9.4, respectively. There were significant differences between localities, but overall the effects of substrate and species followed the same pattern.

Small plants of $Q$. ilex showed more damage than large plants $\left(F_{1,5}=6.07, P=0.019\right)$, but no significant differences were found between the two size classes considered in E. arborea $\left(F_{1,5}=0.01, P=0.929\right)$ (Fig. 3).

One year after the drought event, many plants recovered the canopy from resprouts arising from crown and stumps. In Q. ilex, $43.1 \%$ of the resprouting plants recovered only from shoots arising in the crown, $33.1 \%$ only from shoots growing in the stump and

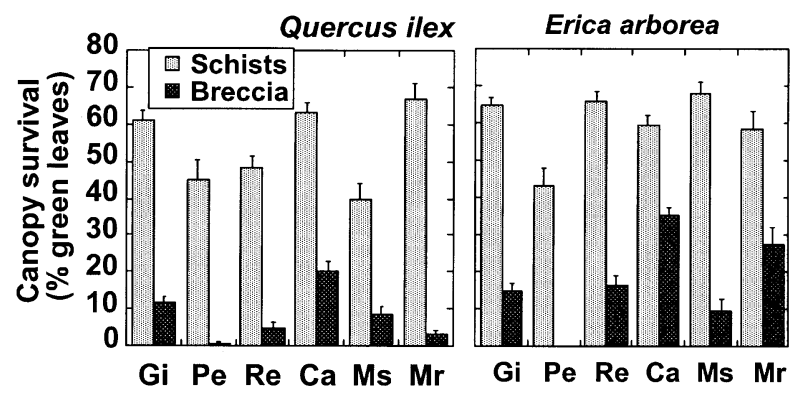

Fig. 2 Effect of the 1994 drought on Quercus ilex and Erica arborea plants growing on two lithological substrates (schists and breccia) in six localities of NE Spain. Values are the mean percentage of remaining green foliage in summer 1994. Error bars show standard error values. Asterisks indicate significant differences $(P<0.0001)$ between schists and breccia. See Table 1 to know the number of plants sampled in each locality. 
23.8\% from both crown and stump shoots. Plants resprouting only from crown showed better recovery (from $14.9 \%$ of green leaves in 1994 to $43.3 \%$ in 1995) than plants recovering from both crown and stump (from $10.2 \%$ to $26.9 \%$ ) or only from stump (from $11.6 \%$ to $22.8 \%$ ) (repeated measures ANOVA, Recover $\times$ Resprouting type interaction $F_{2,468}=29.4, P<0.0001$ ). In E. arborea, $33.3 \%$ of the plants resprouted only from the crown, $20.2 \%$ only from the stump and $46.5 \%$ from both crown and stump. Type of resprouting, however, did not influence significantly the recovery in this species (Recover $\times$ Resprouting type interaction $F_{2,595}=0.20, P<0.818$ ).

The shrub E. arborea recovered better (from $41.4 \%$ of green leaves in 1994 to $63.5 \%$ in 1995) than the tree $Q$. ilex (from $32.8 \%$ to $43.6 \%$ ), as shown by the significant interaction between recovery and substrate (repeated

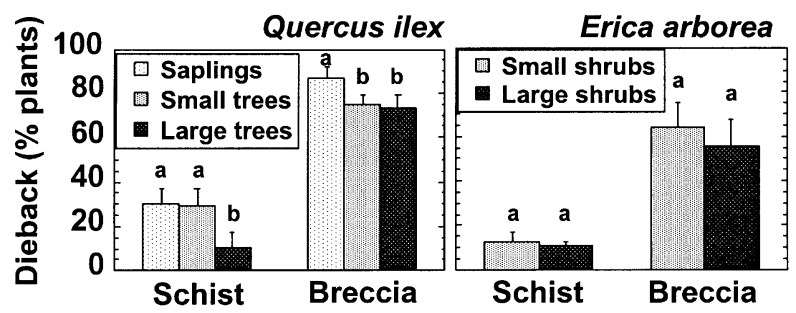

Fig. 3 Effect of the 1994 drought according to plant size and lithological substrate. The values are the percentage of Quercus ilex and Erica arborea plants belonging to the damage class 0 (no remaining green foliage). Values were obtained as the percentage of six localities, and error bars correspond to the standard error. Different letters indicate significant differences between size classes $(P<0.05$, Tukey-Kramer post hoc test after randomized block ANOVA). measures ANOVA, Species $\times$ Recover interaction $\left.F_{1,2501}=129.2, \quad P<0.0001\right)$. Although plants growing on breccia substrate started from a more damaged state, they recovered better than plants established on schist. This pattern was more evident in E. arborea (28.3\% and $16.3 \%$ of recovered leaves in breccia and schist, respectively; repeated measures ANOVA, Recover $\times$ Substrate interaction $F_{1,1234}=64.4, \quad P<0.0001$ ) than in $Q$. ilex $(12.5 \%$ and $9.0 \%$ of recovered leaves in breccia and schist, respectively; repeated measures ANOVA, Recover $\times$ Substrate interaction $F_{1,1265}=7.9$, $P=0.005)$. It was mostly because of the recovery from the class 0 (no remaining green foliage) to the class 1 (up to 25\% green foliage) (Table 2). As a result, in 1995, the percentage of $Q$. ilex plants that still had no live canopy was 38.3 on breccia, and 10.6 on schist. The percentages for E. arborea were 14.3 on breccia and 2.4 on schist.

Plant size did not influence $Q$. ilex canopy recovery, as shown by the not-significant interaction between recover and plant size (repeated measures ANOVA, $F_{1,1265}=1.2$, $P=0.287$ ). The difference in the percentage of green leaves between the 1994 and 1995 surveys was very similar for the three size classes (10.6, 9.8, and 12.2, respectively). These differences were higher in E. arborea (20.0 and 23.4), indicating that large plants had a slightly higher ability to recover, as supported by the significant interaction between recovery and plant size in this species (Repeated measures ANOVA, $F_{1,1234}=4.5, P=0.033$ ).

In 1995, recovery had not modified the patterns of damage observed 1 year before: more damage was observed in breccia than in schist $\left(F_{1,5}=45.49\right.$, $P=0.001$ ), and in $Q$. ilex trees than in E. arborea shrubs $\left(F_{1,5}=69.30, P<0.001\right)$. Smaller plants of $Q$. ilex were

Table 2 Transition matrices between damage categories (percentage of green foliage from the end of the drought period (1994) to one year later (1995). The matrices show the probabilities of transition for Q. ilex and E. arborea plants in the two substrates (schist and breccia)

\begin{tabular}{|c|c|c|c|c|c|c|c|c|c|}
\hline & & \multicolumn{4}{|l|}{ Schist } & \multicolumn{4}{|l|}{ Breccia } \\
\hline & & \multicolumn{4}{|l|}{ From 1994} & \multicolumn{4}{|l|}{ From 1994} \\
\hline & & $\begin{array}{l}\text { No green } \\
\text { foliage }\end{array}$ & $1-25$ & $26-75$ & $76-100$ & $\begin{array}{l}\text { No green } \\
\text { foliage }\end{array}$ & $1-25$ & $26-75$ & $76-100$ \\
\hline \multicolumn{10}{|c|}{ (a) Quercus ilex } \\
\hline \multirow[t]{4}{*}{ To 1995} & No green foliage & 0.401 & 0.065 & 0.038 & 0.009 & 0.479 & 0.046 & 0.021 & 0 \\
\hline & $1-25 \%$ & 0.368 & 0.348 & 0.047 & 0 & 0.426 & 0.369 & 0.085 & 0 \\
\hline & $26-75 \%$ & 0.163 & 0.261 & 0.264 & 0.045 & 0.068 & 0.416 & 0.277 & 0.048 \\
\hline & $76-100 \%$ & 0.068 & 0.326 & 0.651 & 0.946 & 0.027 & 0.169 & 0.617 & 0.952 \\
\hline \multicolumn{10}{|c|}{ (b) Erica arborea } \\
\hline \multirow[t]{4}{*}{ To 1995} & No green foliage & 0.230 & 0.014 & 0.013 & 0 & 0.186 & 0.019 & 0 & 0.023 \\
\hline & $1-25 \%$ & 0.230 & 0.056 & 0.006 & 0.003 & 0.516 & 0.141 & 0 & 0 \\
\hline & $26-75 \%$ & 0.295 & 0.423 & 0.164 & 0.025 & 0.201 & 0.340 & 0.203 & 0.023 \\
\hline & $76-100 \%$ & 0.245 & 0.507 & 0.817 & 0.972 & 0.097 & 0.500 & 0.797 & 0.954 \\
\hline
\end{tabular}


Table 3 Observed plants and expected values (in brackets) belonging to different resprouting categories after the 1985 and 1994 droughts in the Montcau mountain. Expected values and $\chi^{2}$ tests result belongs to the analysis of the correlation between plant state after the two drought episodes for each size class. Numbers in bold style indicate that observed values are higher than expected

\begin{tabular}{|c|c|c|c|c|}
\hline \multirow{2}{*}{$\begin{array}{l}\text { Resprouting state } \\
\text { after the } 1985 \text { drought }\end{array}$} & \multirow[b]{2}{*}{ State after the 1994 drought } & \multicolumn{3}{|l|}{ Plant size } \\
\hline & & Small & Medium & Large \\
\hline Weak & Dead & $7(3.9)$ & $2(1.4)$ & $1(1.6)$ \\
\hline Weak & Weak resprouting & $10(8.9)$ & $4(1.5)$ & $9(3.4)$ \\
\hline Weak & Strong resprouting & $0(4.2)$ & $0(3.1)$ & $2(7.0)$ \\
\hline Strong & Dead & $3(6.1)$ & $7(7.6)$ & $5(4.4)$ \\
\hline Strong & Weak resprouting & $13(14.1)$ & $6(8.5)$ & $4(9.6)$ \\
\hline \multirow[t]{3}{*}{ Strong } & Strong resprouting & $11(6.8)$ & $20(16.9)$ & $25(20.0)$ \\
\hline & $\chi^{2}(\mathrm{df}=2)$ & 11.30 & 8.61 & 17.71 \\
\hline & $P$-value & 0.0035 & 0.135 & 0.0001 \\
\hline
\end{tabular}

more damaged than larger plants $\left(F_{2,10}=11.96\right.$, $P=0.002)$, but no differences between size classes were observed in E. arborea $\left(F_{1,5}=0.92, P=0.382\right)$.

When analysing the recovery pattern after recurrent drought episodes in the Montcau Mountain, we found that the position on the slope also determined the effect of the drought. The percentage of surviving trees of $Q$. ilex after the 1994 drought was higher in the lower part of the slope (82.4) than in the middle and upper parts (71.4 and 67.5, respectively) $\left(\chi^{2}=6.04\right.$, $\mathrm{df}=2, P=0.048$ ).

The response to a first drought appears as an important factor explaining the ability to recover after further drought episodes. There was a significant correlation between the resprouting response after the two drought episodes: plants that resprouted weakly after the 1985 drought were more prone to die in 1995, or to produce a weak resprouting, than plants that resprouted vigorously $\left(\chi^{2}=27.37, \mathrm{df}=2, P<0.0001\right)$.

Plant size also influenced canopy recovery after recurrent droughts $\left(\chi^{2}=24.67, \mathrm{df}=10, P=0.006\right)$. Small plants were more sensitive to the resulting state after the first episode: those with a weak resprouting after 1985 were more prone to die in 1995 than large plants with a weak resprouting after the first drought (Table 3). However, among plants with a weak resprouting in 1985, plant size did not contribute to explaining the response to a further drought $\left(\chi^{2}=6.83\right.$, $\mathrm{df}=4, P=0.145)$. Among plants with strong resprouting in 1985, large plants also resprouted more strongly in 1995 than small ones $\left(\chi^{2}=12.69\right.$, $\left.\mathrm{df}=4, P=0.013\right)$.

\section{Discussion}

This study reports the effect of extreme climatic events on a Mediterranean-type ecosystem, a climatic situation that is predicted to become more frequent in the future (IPCC, 2001). It also reveals that the effects of global change may also present a patchy pattern in the landscape dimension. Landscape patterns of forest dieback may be convincingly explained by geological substrate, because roots penetrating into the deep water table may provide the supply needed to maintain foliage in periods of low water availability. $Q$. ilex is a Mediterranean tree, considered to be tolerant to water deficit (Savé et al., 1999). It has also been documented as developing extensive root systems (Canadell \& Rodà, 1991). Other studies in the area have shown that the roots of $Q$. ilex are able to penetrate deeper into schist following exfoliation planes, than into breccia, which produces a more compact substrate (Canadell et al., 1999). E. arborea is a large shrub, which may also potentially produce an extensive and deep root system; thus, we can expect a similar pattern of differential root penetration in schist and breccia as shown by $Q$. ilex.

These landscape discontinuities are also present in the Montcau area, where the distribution of soil patches in a dramatically eroded mountain determines vegetation islands, as well as vegetation vulnerability to drought. In these conditions, lateral, superficial fluxes of water may be particularly important, as they buffer local stress. For example, those vegetation islands located at the bottom of the slope were less affected by drought, because of the water run-off from uphill areas on the bare rock surface.

The physiological mechanisms involved in leaves and branches mortality under extreme drought have been explored in several species of the region. The hydraulic properties associated to xylem embolism have been suggested as playing a relevant role in explaining the mortality pattern of different pine species (Martínez-Vilalta \& Piñol, 2002). Leaf isotopic 
discrimination $\left(\Delta^{13} C\right)$ has been used as an indicator of intrinsic long-term water use efficiency (WUE) in populations affected by the 1994 drought episode (Peñuelas et al., 2000). This study revealed higher WUE in $Q$. ilex than in other trees in the area, such as P. latifolia. This higher vulnerability of $Q$. ilex to water deficit concurs with leaf gas exchange and fluorescence measurements obtained under experimental conditions (Filella et al., 1998). The effects of the drought remained up to 3 years after the episode ('memory effect'). This delayed effect suggests that the individuals that are most severely damaged in a first episode will be more vulnerable to further drought events. This prediction is supported by our observations in the Montcau survey of recurrent drought episodes, where plants with less vigorous resprouting after the 1985 drought were also less able to regenerate after the 1994 episode.

The two species have a well-known ability to resprout after disturbances from stumps, root crowns or superficial roots (Canadell et al., 1991). This vigour in resprouting in Mediterranean woody species should be because of the water availability after the disturbance (Cruz et al., 2002), the available bud bank (Canadell et al., 1991) and the ability to mobilize resources from underground organs (Canadell \& López-Soria, 1998). In the studied community, the dominant tree species (Q. ilex) was more severely damaged and resprouted less vigorously than $E$. arborea, a large shrub. In $E$. arborea, resprouting from the stump played the same role on canopy recovery than the resprouting of shoots originated in the crown; in $Q$. ilex, the role from stumps was not so important. Therefore, in a scenario of frequent drought episodes, a shift in the dominant species leading to a grater relevance of shrubs may be hypothesized. This trend is reinforced by the observed massive germination of small shrubs, such as Cistus sp. $\mathrm{pl}$ and Rosmarinus officinalis.

Smaller $Q$. ilex plants, particularly saplings and small trees, were more affected by drought. This differential response is probably because of the deeper root systems of larger plants. However, the ability to recover after drought was similar for the three class sizes. After the rainfall of September 1994, the water filled the upper layers of the soil, making the ability of the different class sizes to reach the deep water table less relevant. As a result of both the direct effect of the drought in 1994 and the later recovery, in 1995 the smaller plants had experienced the highest mortality. The effects of drought on plant size do not appear so important in E. arborea, although the postdrought resprouting is more vigorous in larger plants, as supported from experimental disturbances that showed a positive correlation between the number and the biomass of resprouts and plant size (Canadell et al., 1991). This differential response in relation to plant size may produce changes in the population structure, selecting against small classes.

The global change effects on the Mediterranean climate are likely to produce more frequent and longer droughts, similar to that of 1994 . The consequences of drought-related dieback may be multiple: species composition modification, particularly of dominant species, alterations in the nutrient and water balances or increasing fuel load, which promotes fire propagation. Dieback variability across different lithological substrates cannot be predicted from the observations made in climatically normal years. However, it increases dramatically under extreme conditions, suggesting that changes may occur in an episodic, nongradual way. Recurrent droughts would produce a progressive loss of resilience, by depleting the ability of surviving plants to regenerate. Eventually, a single drought episode may be the precipitating event of what could be considered a vegetation shift. Thus, managers should be aware that the consequences of climate change may not show a gradual pattern, but instead, nonlinear responses, and thresholds may result in abrupt shifts in ecosystem function (Woodward \& Beerling, 1997; Scheffer et al., 2001), as represented by forest dieback.

\section{Acknowledgements}

We want to dedicate this paper to the memory of Dr Ramon Margalef. We thank Josep Peñuelas and Jaume Terradas for their suggestions on the manuscript and Josep Canadell for his scientific support. This research was supported by the 6th EU framework programme ALARM (contract 506675) grant.

\section{References}

Allen CD, Breshears DD (1998) Drought-induced shifts of a forest woodland ecotone: rapid landscape response to climate variation. Proceedings of the National Academy of Sciences USA, 95, 14839-14842.

Canadell J, Djema A, López B et al. (1999) Structure and dynamics of the root system. In: Ecology of Mediterranean Evergreen Oak Forests (eds Rodà F, Gracia C, Retana J, Bellot J), pp. 47-59. Springer, Berlin.

Canadell J, Lloret F, López-Soria L (1991) Resprouting vigour of two mediterranean shrub species after experimental fire treatments. Vegetatio, 95, 119-126.

Canadell J, López-Soria L (1998) Lignotuber reserves support regrowth following clipping of two Mediterranean shrubs. Functional Ecology, 12, 31-38.

Canadell J, Rodà F (1991) Root biomass of Quercus ilex in a montane Mediterranean forest. Canadian Journal of Forestry Research, 21, 1771-1778.

Canadell J, Zedler PH (1995) Underground structures of woody plants in Mediterranean ecosystems of Australia, California 
and Chile. In: Ecology and Biogeography of Mediterranean Ecosystems in Chile, California and Australia (eds Fox M, Arroyo MK, Zedler PH), pp. 177-210. Springer, Berlin.

Carrión JS, Munuera M, Dupré M et al. (2001) Abrupt vegetation changes in the Segura Mountains of southern Spain throughout the Holocene. Journal of Ecology, 89, 783-797.

Cruz A, Pérez B, Quintana JR et al. (2002) Resprouting in the Mediterranean-type shrub Erica australis affected by soil resource availability. Journal of Vegetation Science, 13, 641-650.

Díaz-Delgado R, Lloret F, Pons X et al. (2002) Satellite evidence of decreasing resilience in Mediterranean plant communities after recurrent wildfires. Ecology, 83, 2293-2303.

Fensham RJ, Holman JE (1999) Temporal and spatial patterns in drought-related tree dieback in Australian savanna. Journal of Applied Ecology, 36, 1035-1050.

Filella I, Llusià J, Piñol J et al. (1998) Leaf gas exchange and fluorescence of Phillyrea latifolia, Pistacia lentiscus and Quercus ilex saplings in severe drought and high temperature conditions. Environmental Experimental Botany, 39, 213-220.

Hobbs RJ, Mooney HA (1995) Effects of episodic rain events on Mediterranean-climate ecosystems. In: Time Scales of Biological Responses to Water Constraints (eds Roy J, Aronson J, Di Castri F), pp. 71-85. SPA Academic Pub, The Hague.

Hurtt GC, Moorcroft PR, Pacala SW et al. (1998) Terrestrial models and global change challenges for the future. Global Change Biology, 4, 581-590.

IPCC (2001) Climate Change 200: the Scientific Basis. Contribution of Working Group I. In: Third Assessment Report of the Intergovernmental Panel on Climate Change (eds Houghton JT, Ding Y, Griggs DJ, Noguer M, van der Linden PJ, Dai X, Maskell K, Johnson CA), Cambridge University Press, Cambridge.

Malanson GP, Trabaud L (1987) Ordination analysis of components of resilience of Quercus coccifera garrigue. Ecology, 68, 463-472.

Martínez-Vilalta J, Piñol J (2002) Drought-induced mortality and hydraulic architecture in pine populations of the NE Iberian Peninsula. Forest Ecology and Management, 161, 247-256.
Ninyerola M, Pons X, Roure JM (2000) A methodological approach of climatological modelling of air temperature and precipitation through GIS techniques. International Journal of Climatology, 20, 1823-1841.

Palutikof JP, Wigley TML (1996) Developing climate change scenarios for the Mediterranean region. In: Climate Change and the Mediterranean (eds Jeftic L, Keckes S, Pernetta JC), pp. 2756. Arnold, London.

Peñuelas J, Filella I, Lloret F et al. (2000) Effects of a severe drought on water and nitrogen use by Quercus ilex and Phillyrea latifolia. Biologia Plantarum, 43, 47-53.

Peñuelas J, Lloret F, Montoya R (2001) Severe drought effects on Mediterranean woody flora in Spain. Forest Science, 47, 214-218.

Savé R, Castell C, Terradas J (1999) Gas exchange and water relations. In: Ecology of Mediterranean Evergreen Oak Forests (eds Rodà F, Retana J, Gracia CA, Bellot J), pp. 135-147. SpringerVerlag, Berlin.

Scheffer M, Carpenter S, Fley JA et al. (2001) Catastrophic shifts in ecosystems. Nature, 413, 591-596.

Scherm H, van Bruggen AHC (1994) Global warming and nonlinear growth: how important are changes in average temperature? Phytopathology, 84, 1380-1384.

Steffan WL, Cramer W, Ploechl M et al. (1996) Global vegetation models: incorporating transient changes to structure and composition. Journal of Vegetation Science, 7, 321-328.

Summer GN, Romero R, Homar V et al. (2003) An estimate of the effects of climate change on the rainfall of Mediterranean Spain by the late twenty first century. Climate Dynamics, 20, 789-805.

Terradas J (1999) Holm oak and holm oak forests: an introduction. In: Ecology of Mediterranean Evergreen Oak Forests (eds Rodà F, Retana J, Gracia CA, Bellot J), pp. 3-14. SpringerVerlag, Berlin.

Villalba R, Veblen TT (1998) Influences of large-scale climatic variability on episodic tree mortality in northern Patagonia. Ecology, 79, 2624-2640.

Woodward FI, Beerling DJ (1997) The dynamics of vegetation change: health warnings for equilibrium 'dodo' models. Global Ecology and Biogeography Letters, 6, 413-418. 